\title{
REVIEW
}

\section{Screening for coeliac disease in type 1 diabetes}

\section{G K T Holmes}

Arch Dis Child 2002;87:495-499

The average prevalence of coeliac disease among children with diabetes mellitus in 26 reports was $4.5 \%$ (0.97-16.4\%). Malabsorption, unstable diabetes, and growth failure, indicate that coeliac disease may be present. Even those who are apparently asymptomatic may have subtle complaints indicative of coeliac disease if a careful history is taken. III health may only be recognised in retrospect following the benefits conferred by a gluten free diet. For these reasons it is recommended that a screening programme should be instituted to detect coeliac disease in these children. Parents and where possible children themselves, should be fully involved at all stages of the screening, diagnostic, and treatment process.

See end of article for author's affiliation

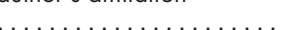

Correspondence to: Dr G K T Holmes, Consultant

Gastroenterologist, Department of Medicine, Derbyshire Royal Infirmary, London Road, Derby

DE 1 2QY, UK;

GeoffreyHolmes@

compuserve.com

Accepted 25 July 2002
C oeliac disease (CD) is now one of the commonest chronic disorders encountered in the western world, with a prevalence as high as $1.3 \%$ in recent screening studies in children. ${ }^{1}$ The advent of serological tests that measure antigliadin (AGA), antireticulin (ARA), antiendomysial (AEA), and antitissue transglutaminase (AtTG) antibodies has greatly aided the diagnosis. In terms of sensitivity and specificity the latter two investigations are preferred. It should be stressed that a small intestinal biopsy is still necessary to confirm the diagnosis. Many disorders have been found in association with CD, but the majority are chance occurrences. ${ }^{2}$ However, type 1 diabetes mellitus and thyroid disease, and some other conditions with a possible immunological aetiology, occur more commonly than by chance alone. Type 1 diabetes mellitus is the commonest and best researched associated condition and the question addressed in this article is whether screening for CD in type 1 diabetes mellitus should become routine in paediatric practice. An article that relates to adults is available. ${ }^{3}$

\section{COELIAC DISEASE AND DIABETES}

The association of childhood diabetes mellitus and CD was first reported over 40 years ago. ${ }^{45} \mathrm{In}$ an early clinical investigation of 400 children with diabetes mellitus, six were found to have CD on small intestinal biopsy. All presented with classical symptoms and improved on a gluten free diet (GFD) with fewer hypoglycaemic episodes. ${ }^{6}$ The authors commented that the diagnosis of CD was sometimes delayed because of the preoccupation with diabetes. Among 300 children with diabetes, eight had symptoms of CD with stunted growth. ${ }^{7}$ All had steatorrhoea, and jejunal biopsies carried out in six showed villous atrophy. In these six, control of diabetes was poor, and in five, hypoglycaemic convulsions frequently occurred. Adherence to GFD was poor. A screening study of 215 children with diabetes found that nine had ARA in the serum, all of whom had small intestinal biopsy specimens taken. ${ }^{8}$ Four new cases of CD were found, and as one was already known in the group the prevalence was 1:43. None of these children had diarrhoea or symptoms of malabsorption but did have some symptoms that could be attributed to $\mathrm{CD}$. Since then, many screening studies have been carried out in children, yielding a prevalence of $\mathrm{CD}$ between 0.97 and $16.4 \%$ (table 1). ${ }^{8-33}$ With regard to the last figure, it is of interest that coeliac disease is very common among children from the Sahara, with 5-6\% affected. ${ }^{34}$

The increased prevalence of $\mathrm{CD}$ in type 1 diabetes can partly be explained by the presence of the common HLA markers B8 and DR3 ${ }^{911}{ }^{12}$ and the DQB ${ }^{*} 0201$ allele that encodes a particular heterodimer. ${ }^{17}{ }^{19}$ It is also of interest that diabetes related autoantibodies may be present in a quarter of patients with CD and may predict the future development of $\mathrm{CD}{ }^{35}$

\section{SCREENING FOR COELIAC DISEASE IN DIABETES}

As CD is so common in type 1 diabetes, the question arises as to whether this group should be screened routinely for this disorder. It is noteworthy that many workers already advocate routine screening in children. ${ }^{812} 1517-1921232627303133$ However, there are a number of points that require consideration. Will health benefits accrue to this group in terms of resolution of symptoms, a reduction in complications associated with coeliac disease, and improved control of diabetes if given a GFD? Will patients comply with a GFD? Is one test enough, and if not, when should subsequent tests be carried out? Is a screening programme cost effective when compared with other such programmes?

\section{PRESENTATION}

In about $90 \%$ of patients diabetes is diagnosed before CD. ${ }^{36}$ In the various reports the numbers of patients with symptoms and signs differ widely, which probably reflects how carefully these were sought. It is likely that some patients were regarded as asymptomatic when they were not.

Abbreviations: AEA, antiendomysial antibodies; $A G A$, antigliadin antibodies; ARA, antireticulin antibodies; AtTG, antitissue transglutaminase antibodies; $C D$, coeliac disease 


\begin{tabular}{|c|c|c|c|c|c|c|c|c|c|}
\hline \multirow{2}{*}{$\begin{array}{l}\text { Ref. } \\
8\end{array}$} & \multirow{2}{*}{$\begin{array}{l}\text { Year } \\
1984\end{array}$} & \multirow{2}{*}{$\begin{array}{l}\text { Country } \\
\text { Finland }\end{array}$} & \multirow{2}{*}{$\begin{array}{l}\text { No. } \\
215\end{array}$} & \multirow{2}{*}{$\begin{array}{l}\text { Screen } \\
\text { ARA }\end{array}$} & \multirow{2}{*}{$\begin{array}{c}\text { +ve screen } \\
9\end{array}$} & \multirow{2}{*}{$\begin{array}{c}\text { No. biopsied } \\
9\end{array}$} & \multirow{2}{*}{$\begin{array}{l}\text { CD by biopsy } \\
4(+1)\end{array}$} & \multicolumn{2}{|c|}{ Prevalence } \\
\hline & & & & & & & & $1: 43$ & $2.3 \%$ \\
\hline 9 & 1986 & Finland & 201 & $\begin{array}{l}\text { AGA } \\
\text { ARA }\end{array}$ & - & - & 7 & $1: 29$ & $3.5 \%$ \\
\hline 10 & 1987 & Italy & 146 & AGA & 9 & 9 & 5 & 1:29 & $3.4 \%$ \\
\hline 11 & 1988 & Germany & 1032 & AGA & 17 & 9 & $2(+8)$ & $1: 103$ & $0.97 \%$ \\
\hline 12 & 1991 & Italy & 498 & AGA & 30 & 22 & 16 & $1: 31$ & $3.2 \%$ \\
\hline 13 & 1992 & Australia & 180 & $A G A$ & 19 & 18 & 4 & $1: 45$ & $2.2 \%$ \\
\hline 14 & 1993 & Sweden & 436 & $\begin{array}{l}\text { AGA } \\
\text { ARA }\end{array}$ & 28 & 26 & $15(+6)$ & $1: 21$ & $4.8 \%$ \\
\hline 15 & 1993 & USA & 211 & AEA & 10 & 3 & 3 & $1: 70$ & $1.4 \%$ \\
\hline 16 & 1994 & Australia & 273 & $\begin{array}{l}\text { AEA } \\
\text { AGA }\end{array}$ & 5 & 5 & 5 & $1: 55$ & $1.8 \%$ \\
\hline 17 & 1996 & Finland & 776 & $\begin{array}{l}\text { AGA } \\
\text { ARA }\end{array}$ & 36 & 19 & 19 & $1: 41$ & $2.4 \%$ \\
\hline 18 & 1996 & Italy & 133 & $\begin{array}{l}\text { AGA } \\
\text { ARA } \\
\text { AEA }\end{array}$ & 6 & 6 & 5 & $1: 27$ & $3.7 \%$ \\
\hline 19 & 1996 & Italy & 172 & AGA & 7 & 7 & 6 & $1: 29$ & $3.5 \%$ \\
\hline 20 & 1996 & Algeria & 116 & $\begin{array}{l}\text { AGA } \\
\text { AEA }\end{array}$ & 13 & 13 & $16 *(+3)$ & $1: 6$ & $16.4 \%$ \\
\hline 21 & 1996 & Spain & 141 & AGA & 12 & 12 & $4(+2)$ & $1: 24$ & $4.2 \%$ \\
\hline 22 & 1997 & Italy & 200 & $\begin{array}{l}\text { AGA } \\
\text { AEA }\end{array}$ & 14 & 11 & 8 & $1: 25$ & $4.0 \%$ \\
\hline 23 & 1998 & Canada & 236 & AEA & 19 & 17 & 12 & $1: 20$ & $5.0 \%$ \\
\hline 24 & 1998 & UK & 167 & $\begin{array}{l}\text { AEA } \\
\text { AGA }\end{array}$ & 11 & 9 & 8 & $1: 21$ & $4.8 \%$ \\
\hline 25 & 1998 & Spain & 93 & $\begin{array}{l}\text { AEA } \\
\text { AGA }\end{array}$ & 7 & 7 & 6 & $1: 16$ & $6.45 \%$ \\
\hline 26 & 1998 & Spain & 177 & $\begin{array}{l}\text { AEA } \\
\text { AGA }\end{array}$ & - & - & $3(4)$ & $1: 25$ & $4.0 \%$ \\
\hline 27 & 1999 & Sweden & 115 & $\begin{array}{l}\text { AEA } \\
\text { AGA }\end{array}$ & 9 & 6 & $5(+2)$ & $1: 16$ & $6.2 \%$ \\
\hline 28 & 2000 & Austria & 403 & $\begin{array}{l}\text { AEA } \\
\text { AGA }\end{array}$ & 14 & 13 & 6 & $1: 67$ & $1.5 \%$ \\
\hline 29 & 2000 & Germany & 520 & $\begin{array}{l}\text { AtTG } \\
\text { AEA } \\
\text { AGA }\end{array}$ & 23 & 13 & 9 & $1: 58$ & $1.7 \%$ \\
\hline 30 & 2001 & Canada & 233 & $\begin{array}{l}\text { AEA } \\
\text { AtTG }\end{array}$ & 19 & 18 & $14(+4)$ & $1: 13$ & $7.7 \%$ \\
\hline 31 & 2001 & USA & 218 & AEA & 17 & 14 & 10 & $1: 22$ & $4.6 \%$ \\
\hline 32 & 2001 & Denmark & 106 & $\begin{array}{l}\text { AGA } \\
\text { AEA } \\
\text { AtTG }\end{array}$ & 10 & 9 & $9(+2)$ & $1: 10$ & $10 \%$ \\
\hline 33 & 2002 & Italy & 274 & EMA & 27 & 20 & $16(+1)$ & $1: 16$ & $6.2 \%$ \\
\hline
\end{tabular}

*Three patients with negative serology biopsied on clinical grounds and all had coeliac disease. Numbers in brackets indicate patients with coeliac disease diagnosed before screening.

Furthermore, ill health may only be recognised retrospectively, following the benefits conferred by adopting a GFD. This is well illustrated in the following instance. A child of 5 years was diagnosed with diabetes, and at the age of 9 a screening test for CD was positive; the diagnosis was confirmed by a small intestinal biopsy. He had not gained weight in the previous year but his parents considered him to be asymptomatic. I quote with permission from a letter that his mother sent me.

"We did not consider that he had any of the symptoms indicating coeliac disease, but decided to put him onto a GFD to see what would happen, and in fact there have been notable improvements. He was growing at an apparently normal rate before the GFD, but has grown notably in the five months since the diet was started. He has also put on weight and his diabetic control, while never too bad, has improved, particularly when we look at his $\mathrm{HbAlc}$ results over the past three months. Another unlooked for but welcome effect has been improved serenity in his general demeanour. He has always been a happy go lucky and cheerful boy, but in the past year we had noticed that he was becoming increasingly irritable. We had put this short temperedness down to his frustration with his diabetes and also considered it to be a product of his growing up. However, following the GFD he has reverted to his former happy self. We are managing the diet very well at home and his school has been extremely supportive and provided excellent alternative school lunches for him. Thus, although my initial inclination was to leave well alone we are glad that we did begin following the GFD."

Examples like this are plentiful and caution against too readily labelling patients as asymptomatic when they are not.

At the time of screening, most children do not complain of gastrointestinal disturbances, ${ }^{8-11} 13151618212226293133$ but failure to thrive $\mathrm{e}^{241}$ and gastrointestinal symptoms ${ }^{14} 2426{ }^{30-33}$ may be present, and in some cases may only be recognised in retrospect. ${ }^{14}{ }^{24}$ Short stature has been reported in about one third of children, ${ }^{12}{ }^{19}{ }^{36}$ but in some series is not a feature..$^{1537}$ Delayed puberty may occur, ${ }^{819}$ and hypertransaminasaemia, ${ }_{19} 303238$ anaemia, ${ }^{30} 32$ iron deficiency, ${ }^{19} 33$ arthralgia, ${ }^{8}{ }^{19}$ dental enamel defects, ${ }^{32}$ hypoglycaemia, and a reduction of insulin requirements ${ }^{39}$ may indicate the presence of coeliac disease in children. Children with $\mathrm{CD}$ and diabetes are younger at the onset of diabetes than those without $\mathrm{CD}_{,}{ }^{11}{ }^{32}$ but this has been disputed. ${ }^{33}$ 


\section{VALUE OF A GLUTEN FREE DIET Features of coeliac disease}

A GFD dramatically improves the great majority of patients with CD, and this also prevails in those with associated diabetes. Improvement has been noted in symptoms, ${ }^{14243133}$ with a sense of improved wellbeing and vitality, growth in children, ${ }^{18} 19$ serum antibody levels, ${ }^{8} 1014192427$ haemoglobin concentration and mean red cell volume, ${ }^{33}$ and in the architecture of the small intestinal mucosa. ${ }^{89131424}$

\section{Control of diabetes}

In early clinical studies, CD was diagnosed in patients with diabetes because they had malabsorption. When this was corrected by adopting a GFD, diabetic control usually improved, with a reduction in hypoglycaemic episodes. ${ }^{6}$ In patients detected by screening, the influence of a GFD on diabetic control as judged by insulin requirements and glycosylated haemoglobin has been variable. Some report no effect, ${ }^{9}{ }^{13} 242837$ or improved control ${ }^{1321}$ with less hypoglycaemic episodes. $^{141939}$ In some cases adherence to a GFD was not strict, making a proper assessment difficult.

\section{Complications and associations}

Adult CD is associated with a number of complications, the most serious of which is lymphoma. ${ }^{40}{ }^{41}$ It has been shown that a strict GFD taken for at least five consecutive years protects against the development of this malignancy. ${ }^{41}$ While lymphoma is reported to occur in children with $\mathrm{CD}$, it is extremely rare. $^{42}$ In some adults the onset of lymphoma precipitates the diagnosis of $\mathrm{CD}$; prior to this event, $\mathrm{CD}$ was latent or silent. ${ }^{43}$ It could be argued that an earlier screened diagnosis of CD and treatment with a GFD might have prevented the onset of lymphoma. Lymphoma has been found in association with type 2 diabetes in some studies, ${ }^{44-46}$ but not others. ${ }^{47}$ Of four patients with type 1 diabetes, two had enteropathy associated $\mathrm{T}$ cell lymphoma. ${ }^{48}$ Investigations to determine causes of death in diabetes are difficult to carry out, and it may well be that more are dying of lymphoma that presently thought. This area requires further exploration.

Osteoporosis is another important occurrence in CD, but it is not clear how this translates into fracture risk. Children with CD may also be affected by osteoporosis. It is improved by a GFD. A reduction of bone mineral density is a feature of diabetes, particularly type $1{ }^{49}{ }^{50}$ and predisposes to low energy fractures. ${ }^{50}$ It has been suggested that CD should be considered a possible cause of osteopenia in type 1 diabetic patients found to have a reduced bone mineral density. ${ }^{51}$ Lymphoma and osteoporosis may affect asymptomatic coeliac patients. ${ }^{40}$

Other health risks in CD include neurological disorders, epilepsy, and problems associated with reproduction-in particular, late menarche and early menopause, infertility, miscarriages, and low birthweight babies. A GFD may have a beneficial effect on some of these disorders and it could be argued that the earlier the detection and treatment of $\mathrm{CD}$, the better for the patient in this regard.

An increased prevalence of autoimmune disorders occurs in patients with $\mathrm{CD}^{52}{ }^{53}$ and evidence exists to show that the longer the exposure to gluten in patients with $\mathrm{CD}$, the more likely is the development of autoimmune diseases. ${ }^{52}$ The corollary of this is that a GFD might protect against the development of these disorders, perhaps by clearing certain autoantibodies, for example, those which are thyroid related, from the circulation..$^{54}$

\section{EXPRESSIONS OF COELIAC DISEASE AND IMPLICATIONS FOR SCREENING STRATEGIES}

With expanding knowledge of the natural history of CD it has become recognised that gluten sensitivity is wider than previously thought, and incorporates latent and potential CD. ${ }^{55}$ Latent $\mathrm{CD}$ is defined by a normal biopsy in patients taking a normal diet who, at some other time, before or since, have had a flat biopsy that recovers on a GFD. Before these patients develop a flat biopsy they have the potential to do so, and hence the term "potential coeliac disease" was proposed to define this phase of the disorder. In potential CD the upper small intestinal mucosa has normal looking villi, but subtle changes are present such as an increased number of intraepithelial lymphocytes bearing the $\gamma / \delta \mathrm{T}$ cell receptor and aberrant HLA-DR expression in the crypts. AEA may be present and in time the mucosa may become flat. ${ }^{56}$ Patients with diabetes may have potential or latent CD, 22262830313357 and this has implications for screening strategies.

Coeliac disease was searched for at the diagnosis of diabetes, and at 6, 12, 18, 24, and 36 months, and thereafter among 776 children with diabetes by the detection of AGA and ARA. ${ }^{17}$ At the diagnosis of diabetes, CD was confirmed in nine serologically positive patients by small intestinal biopsy. Nine who were serologically negative developed antibodies within two years and had CD confirmed by biopsy. Others have drawn attention to the importance of serial screening but it is uncertain what the time interval between tests should be. Some have supported screening at the diagnosis of diabetes and then annually. ${ }^{19} 273$ Others favour screening at diagnosis, and then at 1,3 , and 5 years. ${ }^{17}$ It has also been advocated that screening should be carried out $1-2$ years after the diagnosis of diabetes to allow the tests to become positive. ${ }^{112}$ AGA may be present as a transient phenomenon at the onset of diabetes and may just reflect disturbed immunity or an increase in intestinal permeability at this time. ${ }^{1122} 2627{ }^{32}{ }^{58-60}$ AEA may also occur transiently. ${ }^{33}$ Until more information becomes available, one strategy would be to screen at the diagnosis of diabetes and annually for three years, then at 5 years, and then five yearly thereafter or at any other time if there are clinical indications.

It has been suggested that screening should be offered to first degree relatives of those with type 1 diabetes because they frequently have silent $C D{ }^{53}{ }^{61}$ Those relatives with the HLA DRB1*03 $\mathrm{DQAl} * 05 \mathrm{DQB1}$ *02 (DR3-DQ2) haplotype require particular attention because AtTG and AEA were more prevalent in this subgroup. Others have also focused attention on those first degree relatives with the $\mathrm{DQB1}{ }^{*} 02$ allele. ${ }^{62}$

\section{COST OF A SCREENING PROGRAMME}

Assuming a prevalence in the general population of type 1 diabetes of $0.4 \%$, then for a hospital serving a population of 500000 there would be 2000 existing patients. If these were screened at 1,5 , and 10 years, it can be calculated that the cost per case diagnosed would be $£ 860$, assuming that a serological test costs about $£ 10$ and a diagnostic upper gastrointestinal endoscopy $£ 280$. The incidence of type 1 diabetes in the UK is about 15-20 per 100000 new cases per year. Based on the lower figure, 75 new cases would occur in a population of 500000 . If these were screened at diagnosis and 1,2, 3, 5, and 10 years over a decade, the cost per case would be $£ 950$. Screening type 1 diabetics over the subsequent decades would incur similar costs. These expenses should be set against expenditure on unnecessary investigations, treatments, clinic visits, and admissions for those with type 1 diabetes who are ill with unrecognised coeliac disease as well as the consequences to health and wellbeing. These costs compare very favourably against other well established screening programmes; for example, for congenital hypothyroidism the median cost per true case has been estimated at $£ 14960$, for cystic fibrosis $£ 4500$, and for phenylketonuria $£ 25000$. ${ }^{63}$

\section{CONCLUSIONS}

In children $\mathrm{CD}$ and type 1 diabetes mellitus are frequently associated. Malabsorption, unstable diabetes, and growth failure indicate the possible presence of CD. Even those who are thought to be asymptomatic may have subtle complaints such 
as gastrointestinal upsets if a careful history is elicited. It is important to understand that in some, ill health may only be recognised in retrospect following the benefits conferred by a GFD.

A screening programme for $\mathrm{CD}$ is preferable to a case finding approach, because of the high prevalence of coeliac disease in type 1 diabetes, and ensures all cases would eventually be identified.

Parents and children themselves if possible, should receive a full explanation of the case for screening. Those who give consent to be tested would then, if found to have CD, be in a position to make informed choices about how they would like to proceed. Some will want to start a GFD and should be introduced to a sympathetic dietician skilled in managing diabetic and gluten free diets. Some who are serologically positive may not wish a confirmatory small bowel biopsy, while some who do have CD confirmed may not accept a GFD. Such patients could then be monitored carefully for the appearance of symptoms of anaemia, deficiencies of folate, iron, or calcium, growth failure, or unexplained difficulties in achieving control of diabetes, in which case prompt action could be taken.

\section{Author's affiliation}

G K T Holmes, Department of Medicine, Derbyshire Royal Infirmary, Derby, UK

\section{REFERENCES}

1 Carlsson AK, Axelsson IE, Borulf SK, et al. Serological screening for celiac disease in healthy 2.5 -year-old children in Sweden. Pediatrics $2001 ; 107: 42-5$

2 Collin P, Reunala T, Pukkala E, et al. Coeliac disease-associated disorders and survival. Gut 1994;35:1215-18.

3 Holmes GKT. Coeliac disease and type 1 diabetes mellitus-the case for screening. Diabet Med 2001;18:169-77.

4 Walker-Smith JA, Grigor,W. Coeliac disease in a diabetic child [letter]. Lancet 1969;1:1029.

5 Visakorpi JK. Diabetes and coeliac disease [letter]. Lancet 1969;2:1192.

6 Thain ME, Hamilton JR, Ehrlich RM. Coexistence of diabetes mellitus and celiac disease. J Pediatr 1974;85:527-9.

7 Sires JM, de Majo SF. Diabetes and coeliac disease in children. Pediatr Adolesc Endocr 1977;2:227-33.

8 Maki M, Hallstrom O, Huupponen T, et al. Increased prevalence of coeliac disease in diabetes. Arch Dis Child 1984;59:739-42.

9 Savilahti E, Simell O, Koskimies S, et al. Celiac disease in insulin-dependent diabetes mellitus. J Pediatr 1986;108:690-3.

10 Cacciari E, Salardi S, Volta U, et al. Prevalence and characteristics of coeliac disease in type 1 diabetes mellitus. Acta Paediatr Scand 1987;76:671-2

11 Koletzko S, Burgin-Wolff A, Koletzko B, et al. Prevalence of coeliac disease in diabetic children and adolescents. A multicentre study. Eur J Pediatr 1988;148:113-17.

12 Barera G, Bianchi C, Calisti L, et al. Screening of diabetic children for coeliac disease with antigliadin antibodies and HLA typing. Arch Dis Child 1991;66:491-4

13 Gadd S, Kamath KR, Silink M, et al. Co-existence of coeliac disease and insulin-dependent diabetes mellitus in children: screening sera using an ELISA test for gliadin antibody. Aust N Z J Med 1992;22:256-60.

14 Sigurs N, Johansson C, Elfstrand PO, et al. Prevalence of coeliac disease in diabetic children and adolescents in Sweden. Acta Paediatr 1993; 82:748-51.

15 Rossi TM, Albini CH, Kumar V. Incidence of celiac disease identified by the presence of serum endomysial antibodies in children with chronic diarrhea, short stature, or insulin-dependent diabetes mellitus. J Pediatr 1993; 123:262-4.

16 Verge CF, Howard NJ, Rowley M, et al. Anti-glutamate decarboxylase and other antibodies at the onset of childhood IDDM: a population-based study. Diabetologia 1994;37:1113-20.

17 Saukkonen T, Savilahti E, Reijonen H, et al. Coeliac disease: frequent occurrence after clinical onset of insulin-dependent diabetes mellitus. Childhood Diabetes in Finland Study Group. Diabet Med 1996; 13:464-70

18 Lorini R, Scotta MS, Cortona L, et al. Celiac disease and type I (insulin-dependent) diabetes mellitus in childhood: follow-up study. J Diabetes Complications 1996:10:154-9.

19 Lorini R, Scaramuzza A, Vitali L, et al. Clinical aspects of coeliac disease in children with insulin-dependent diabetes mellitus. J Pediat Endocrinol Metab 1996;9(suppl 1):101-11

20 Boudraa G, Hachelaf W, Benbouabdellah M, et al. Prevalence of coeliac disease in diabetic children and their first-degree relatives in west Algeria: screening with serological markers. Acta Paediatr Suppl 1996;412:58-60.
21 Calero P, Ribes-Koninckx C, Albiach V, et al. IgA antigliadin antibodies as a screening method for nonovert celiac disease in children with insulin-dependent diabetes mellitus. J Pediatr Gastroenterol Nutr 1996;23:29-33.

22 Cacciari E, Bianchi FB, Salardi S, et al. Late development of $\lg A$ antiendomysial antibodies and small intestinal mucosal atrophy after insulin dependent diabetes mellitus onset. Arch Dis Child 1997;77:465.

23 Fraser-Reynolds KA, Butzner JD, Stephure DK, et al. Use of immunoglobulin A-antiendomysial antibody to screen for celiac disease in North American children with type 1 diabetes. Diabetes Care 1998;21:1985-9.

24 Acerini CL, Ahmed ML, Ross KM, et al. Coeliac disease in children and adolescents with IDDM: clinical characteristics and response to gluten-free diet. Diabet Med 1998;15:38-44.

25 Vitoria JC, Castano L, Rica I, et al. Association of insulin-dependent diabetes mellitus and celiac disease: a study based on serologic markers. I Pediatr Gastroenterol Nutr 1998;27:47-52

26 Roldan MB, Barrio R, Roy G, et al. Diagnostic value of serological markers for celiac disease in diabetic children and adolescents. J Pediatr Endocrinol Metab 1998;11:751-6.

27 Carlsson AK, Axelsson IE, Borulf SK, et al. Prevalence of $\lg \mathrm{A}$-antiendomysium and $\lg \mathrm{A}$-antigliadin autoantibodies at diagnosis of insulin-dependent diabetes mellitus in Swedish children and adolescents. Pediatrics 1999; 103:1248-52.

28 Schober E, Bittmann B, Granditsch G, et al. Screening by anti-endomysium antibody for celiac disease in diabetic children and adolescents in Austria. J Pediatr Gastroenterol Nutr 2000;30:391-6.

29 Kordonouri O, Dieterich W, Schuppan D, et al. Autoantibodies to tissue transglutaminase are sensitive serological parameters for detecting silent coeliac disease in patients with type 1 diabetes mellitus. Diabet Med 2000; 17:441-4.

30 Gillett PM, Gillett HR, Israel DM, et al. High prevalence of celiac disease in patients with type 1 diabetes detected by antibodies to endomysium and tissue transglutaminase. Can J Gastroenterol 2001;15:297-301.

31 Aktay AN, Lee PC, Kumar V, et al. The prevalence and clinical characteristics of celiac disease in juvenile diabetes in Wisconsin. J Pediatr Gastroenterol Nutr 2001;33:462-5.

32 Hansen D, Bennedbaek FN, Hansen LK, et al. High prevalence of coeliac disease in Danish children with type I diabetes mellitus. Acta Paediatr 2001;90:1238-43.

33 Barera G, Bonfanti R, Viscardi $M$, et al. Occurrence of celiac disease after onset of type 1 diabetes: a 6 -year prospective longitudinal study. Pediatrics 2002;109:833-8.

34 Catassi C, Ratsch IM, Gandolfi L, et al. Why is coeliac disease endemic in the people of the Sahara? Lancet 1999;354:647-8.

35 Galli-Tsinopoulou A, Nousia-Arvanitakis S, Dracoulacos D, et al. Autoantibodies predicting diabetes mellitus type I in celiac disease. Horm Res 1999;52:119-24.

36 Pocecco $M$, Ventura A. Coeliac disease and insulin-dependent diabetes mellitus: a causal association? Acta Paediatr 1995;84:1432-3.

37 Westman E, Ambler GR, Royle M, et al. Children with coeliac disease and insulin dependent diabetes mellitus - growth, diabetes control and dietary intake. J Pediatr Endocrinol Metab 1999;12:433-42.

38 Lorini R, Maggiore G, De Giacomo C, et al. Elevated serum aminotransferase activity: an early manifestation of gluten-sensitive enteropathy in children with insulin-dependent diabetes mellitus. J Pediatr 1994; 124:995

39 Iafusco D, Rea F, Prisco F. Hypoglycemia and reduction of the insulin requirement as a sign of celiac disease in children with IDDM. Diabetes Care 1998:21:1379-81.

40 Holmes GKT. Non-malignant complications of coeliac disease. Acta Paediatr Suppl 1996;412:68-75.

41 Holmes GKT, Prior P, Lane MR, et al. Malignancy in coeliac disease-effect of a gluten free diet. Gut 1989:30:333-8.

42 Schweizer JJ, Oren A, Mearin ML. Cancer in children with celiac disease: a survey of the European Society of Paediatric Gastroenterology, Hepatology and Nutrition. J Pediatr Gastroenterol Nutr 2001;33:97-100

43 Freeman HJ, Chiu BK. Multifocal small bowel lymphoma and latent celiac sprue. Gastroenterology 1986:90:1992-7.

44 Natazuka T, Manabe $Y$, Kono $M$, et al. Association between non-insulin dependent diabetes mellitus and non-Hodgkin's lymphoma. BM 1994;309: 1269

45 Brody JI. Non-insulin dependent diabetes mellitus and non-Hodgkin's lymphoma. Already reported. BM 1995;310:1009.

46 Cerhan JR, Wallace RB, Folsom AR, et al. Medical history risk factors for non-Hodgkin's lymphoma in older women. J Natl Cancer Inst 1997;89:314-18.

47 Zahm SH, Blair A, Cantor KP, et al. Non-insulin dependent diabetes mellitus and non-Hodgkin's lymphoma. Other American studies fail to confirm an association. BMV 1995:310:1009-10.

48 O'Connor TM, Cronin CC, Loane JF, et al. Type 1 diabetes mellitus, coeliac disease, and lymphoma: a report of four cases. Diabet Med 1999; 16:614-17

49 Forst T, Pfutzner A, Kann P, et al. Peripheral osteopenia in adult patients with insulin-dependent diabetes mellitus. Diabet Med 1995;12:874-9.

50 Tuominen JT, Impivaara O, Puukka P, et al. Bone mineral density in patients with type 1 and type 2 diabetes. Diabetes Care 1999;22:1196-200.

51 Lunt H, Florkowski CM, Cook HB, et al. Bone mineral density, type 1 diabetes, and celiac disease. Diabetes Care 2001:24:791-2.

52 Ventura A, Magazzu G, Greco L. Duration of exposure to gluten and risk for autoimmune disorders in patients with celiac disease. SIGEP 
Study Group for Autoimmune Disorders in Celiac Disease. Gastroenterology 1999;117:297-303.

53 Not T, Tommasini A, Tonini G, et al. Undiagnosed coeliac disease and risk of autoimmune disorders in subjects with type I diabetes mellitus. Diabetologia 2001:44:151-5

54 Ventura A, Elena N, Claudio U, et al. Gluten-dependent diabetes-related and thyroid-related autoantibodies in patients with celiac disease. J Pediatr 2000;137:263-5.

55 Holmes GKT. Potential and latent coeliac disease. Eur J Gastroenterol Hepatol 2001;13:1057-60.

56 Troncone R. Latent coeliac disease in Italy. The SIGEP Working Group on Latent Coeliac Disease. Italian Society for Paediatric Gastroenterology and Hepatology. Acta Paediatr 1995;84:1252-7.

57 Maki M, Huupponen T, Holm K, et al. Seroconversion of reticulin autoantibodies predicts coeliac disease in insulin dependent diabetes mellitus. Gut 1995;36:239-42.
58 Volta U, Bonazzi C, Pisi E, et al. Antigliadin and antireticulin antibodies in coeliac disease and at onset of diabetes in children. Lancet 1987;2:1034-5.

59 Catassi C, Guerrieri A, Bartolotta E, et al. Antigliadin antibodies at onset of diabetes in children. Lancet 1987:2:158.

60 Lorini R, Scotta MS, Avanzini MA, et al. IgA antibodies to gliadin, reticulin, and endomysium for celiac disease screening in children with insulin-dependent diabetes mellitus. J Pediatr 1994;124:994.

61 Hummel M, Bonifacio E, Stern M, et al. Development of celiac disease-associated antibodies in offspring of parents with type I diabetes. Diabetologia 2000;43:1005-11

62 Saukkonen T, llonen J, Akerblom HK, et al. Prevalence of coeliac disease in siblings of patients with type I diabetes is related to the prevalence of $\mathrm{DQB} 1{ }^{*} 02$ allele. Diabetologia 2001;44:1051-3.

63 Pollitt RJ, Green A, McCabe CJ, et al. Economic evaluation of neonatal screening. Health Technology Assessment 1997;1:141-62.

\section{POSTCARD FROM DOWN UNDER The legendary forty-hour working week}

$\mathrm{O}$ e of the many reasons I was keen to work in Australia was to see if they really had achieved what we're told they have-the legendary forty-hour working week. More to the point, how have they reconciled that magical triumvirate: Service, Education, and the often overlooked Having a Life. Let me start by saying that I think that they have achieved it, to some extent, but that I don't quite understand how.

The agreements between junior doctors and their employers are at state level in Queensland, but there are a few generalisations that can be made. Firstly the contract is to 40 hours per week-well, in fact, 80 hours per fortnight. Secondly the employer suffers a series of financial penalties for asking doctors to work antisocial hours or patterns. These range from $15 \%$ extra for night shifts, to double time for Sundays, to $250 \%$ for some public holidays, with many shades of grey between. For example, if you work any overtime or more than 10 hours in a day your hourly rate rises, at this point, to $150 \%$ basic. If you were on what we might understand as a full shift roster, you'd be on $200 \%$ for any overtime. In any case, after three hours of overtime you're on $200 \%$. Confused yet? The Queensland award and interpretation runs to more than 100 pages.

The employer is, therefore, under a large financial pressure to introduce more reasonable-and thus for them cheaperworking patterns in this more sophisticated version of what is being attempted with the banding system in the UK. However, they do have a powerful trump card to play. "Remote on-call", in Queensland at least, requires a doctor to be available for work at 30 minutes' notice. This means, at the very least, staying in town, contactable and sober. For this the doctor is paid just a few dollars a day. Of course, once they are called in they are immediately on penalty rates of pay, but this provision does allow an employer to roster doctors quite tightly, and pay an almost negligible amoun for peace-of-mind backup for busy times or sickness.
Now education. In the UK I've heard the argument, expressed by apparently sensible people, that unless they work the odd 30 hour shift they can't possibly "get experience." My Australian colleagues express incredulity at this: "What? Experience of feeling rooted?" they ask-rooted being a euphemism for "very tired". It seems accepted that you work some bunches of nights, during which you're tired and feel rotten. However, you do most of your learning the rest of the time, and you learn because you are not tired, are (for the most part) adequately supervised, and because you have the time, space, and inclination to study.

What about having a life? I mostly worked 3 different patterns in Australia. In my first placement, on an oncology unit, I worked nine-to-five-really eight to six, with every fourth Friday evening until 10, and every fourth Sunday, thirteen hours. I had to hide my smile when they paid me extra for staying late (I was still in British doctor mode) and had to remind myself to write it all down. One week in eight I was on remote on-call, as described above, but I was only called in once in four months. And yes, I had a life. I could even go out in the evening, plan weekends, buy cinema tickets, and even stay awake during the film... My next pattern was shifts on a paediatric intensive care unit, which was much more disruptive. The upside was the greatly increased pay from all the penalties, enabling me to do a great deal with the little free time I did get. I should add that this was a full roster covered (non-prospectively) by just four people, and therefore unlikely to be replicated in the UK, where at least six or seven people are felt to be the point at which a shift system can be introduced. Lastly I shared an old fashioned one in two with a consultant in a remote country town. Again, not hugely conducive to getting out and about-both the roster and the isolation-but financially rewarding, which I made good use of

As stated, I think it works in Australia. But how would I import the legend to the UK?
This has clearly defeated better minds than mine, but I'd suggest that to get a true improvement, we need a fundamental shift in our attitudes.

Firstly, we've got to get over our night shift hang-ups. Reasonable clusters at reasonable intervals are tolerable, and allow you to provide a lot of service for not too much life disruption. Ditch, also, the idea that you learn a great deal at night-unless learning from your mistakes is your preferred method of learning. Make it up to people by teaching them even better during the day. Make handover a time where doctors are both accountable for their actions, and educated

Secondly, if someone is going to sit around for long periods, let them sit around at home, or somewhere else. Don't pay them full time for this, but do give them a bit more than the Aussies. Then, if you need them, pay them properly for their trouble. You'd pay a plumber $£ 75$ an hour at a weekend if you called them, wouldn't you? But you wouldn't expect to pay him an hourly rate for the rest of the 24 hour period.

Thirdly, I don't think people mind working overtime if this is recognised-that is, that they're paid for it. It alters your perception of staying late (you don't write down every minute, but you are reasonably rewarded for times when you need to work harder) and your employer rapidly recognises when you are being worked too hard.

Lastly, although a very great part of my life is paediatrics, this isn't the same as A Life. A Life means-well, I'm not sure what it means, but I think it is something to do with not being tired all the time, being loving to the people you love, and having time for things outside of work. Until we all appreciate that, we're going to have a long a difficult struggle.

I D Wacogne

Dr Wacogne was on secondment at the Royal Children's Hospital, Brisbane for two years and is now completing his SpR training at the North Staffordshire Hospital, UK. 